\title{
ANÁLISE DO DESENVOLVIMENTO SOCIAL E ECONÔMICO E SEU HISTÓRICO FRENTE A EXPLORAÇÃO DE RECURSOS AMBIENTAIS: REFLEXÃO PARA MELHORES PRÁTICAS SUSTENTÁVEIS.
}

Cláudio Pedrassoli Júnior, Giuliano Mikael Tonelo Pincerato

Universidade do Oeste Paulista - UNOESTE, Mestrado em Meio Ambiente e Desenvolvimento Regional - MMADRE, Presidente Prudente, SP.

\section{RESUMO}

Este trabalho tem o objetivo de levantar os principais aspectos da relação do desenvolvimento social e econômico da Humanidade, fazendo uma breve análise do histórico de exploração ambiental, pela humanidade, para captação de recursos utilizados a seu favor em detrimento do respeito ao equilíbrio necessário para a manutenção da vida de outras espécies e da própria humanidade.

Com base no estudo da bibliografia apresentada foi possível realizar uma análise cultural, social e econômica frente à degradação ambiental, foi concluído que uma mudança de paradigmas nos processos de exploração de recursos naturais é inevitável para a continuidade da vida humana e do equilíbrio ecológico do Planeta.

Palavras-chave: degradação ambiental, epistemologia ambiental, gerenciamento de recursos naturais.

\section{ANALYSIS OF SOCIAL AND ECONOMIC DEVELOPMENT AND ITS HISTORY REGARDING THE EXPLOITATION OF ENVIRONMENTAL RESOURCES: REFLECTION ON SUSTAINABLE BEST PRACTICES.}

\begin{abstract}
ABSTACT
This work has the objective of raising the main aspects of the relation of the social and economic development of Humanity, making a brief analysis of the history of environmental exploration, by humanity, to attract resources used in their favor to the detriment of the respect to the balance necessary for the Maintenance of the life of other species and humanity itself.

Based on the study of the bibliography presented it was possible to perform a cultural, social and economic analysis in the face of environmental degradation, it was concluded that a paradigm shift in the processes of natural resource exploration is inevitable for the continuity of human life and the ecological balance of the Planet
\end{abstract}

Keywords: management of natural resources, environmental degradation, environmental epistemology. 


\section{INTRODUÇÃO}

A humanidade vem evoluindo há milhares de anos, através de sua relação com o meio ambiente. No início de sua cultura, o meio ambiente determinava onde a sociedade humana deveria se abrigar para poder sobreviver e buscar sua subsistência. Nesta época pré-histórica, o meio impunha-se sobre a capacidade de busca de alimento e abrigo necessários para a perpetuação da população humana no planeta.

Com o passar do tempo o homem foi capaz de entender e controlar certos fenômenos naturais primordiais, como o domínio do fogo, que o ajudaram a consolidar formas de defesa, preparo do alimento, manutenção da temperatura e iluminação noturna. Esses benefícios foram incorporados à sua cultura através de rituais, que eram passados de geração em geração para a manutenção da espécie humana.

Outra grande conquista foi o desenvolvimento da agricultura, através da observação da germinação de sementes próximas às áreas de abrigo, onde eram descartados os restos de frutas e vegetais colhidos para consumo. Este foi um grande salto na cultura da humanidade, pois a partir do controle agrícola as populações humanas deixaram de ser nômades e se estabeleceram em determinadas áreas, passando também a dominar a criação de animais em cativeiro para sua subsistência.

O histórico de desastres ecológicos causados pela ação do homem no meio ambiente, durante o desenvolvimento da agricultura, gerou desmatamento de grandes áreas do planeta e a implantação de indústrias, usinas, plataformas petrolíferas, dentre tantas outras formas de extrair e produzir os recursos que julga-se necessário para a sua subsistência e conforto, gerados pela ideia capitalista que move a atual política no mundo, trouxe à tona debates à respeito do esgotamento ambiental e o contingente de pessoas preocupadas com este tema tem aumentado cada vez mais com a repercussão midiática, além dos índices e pesquisas que apontam nesta direção como o Aumento da Temperatura Global, o Degelo das Calotas Polares, o buraco na camada de Ozônio, a Poluição das águas, da atmosfera e do solo, extinção de espécies, dentre outros sabidos.

Os problemas ambientais de ordem antrópica decorrem do uso do meio ambiente para obter os recursos necessários para produzir bens e serviços, proporcionando conforto ao ser humano. O que o homem "acha" (considera) que não serve mais é descartado no ambiente; mas isso nem sempre gerou degradação ambiental em razão da escala reduzida de produção e consumo e da maneira pela qual os seres humanos entendiam sua relação com a natureza e interagiam com ela. SILVA \& CRISPIN (2011, p 164, 165).

Desde os tempos mais remotos até o surgimento das indústrias, os resíduos eram produzidos em pequenas quantidades. Com o crescimento populacional, consequentemente, as indústrias começaram a fabricar novos produtos, aumentando assim consideravelmente o volume e a diversidade dos resíduos gerados.

Na década de 1960 houve um crescente debate principalmente nos Estados Unidos sobre o uso de pesticidas químicos, a responsabilidade da ciência e os limites do progresso tecnológico que vinha alterando dramaticamente o equilíbrio de poder entre os seres humanos e a natureza.

Estas questões começaram a ser levantadas no livro "Primavera silenciosa" escrito por Rachel Carson, suas preocupações eram pautadas por um certo retrocesso quase religioso, onde a população atribuía aos químicos uma sabedoria quase divina, pois os resultados eram vistos apenas por uma ótica de benefício no aumento da produtividade, deixando de lado o fato de que os seres humanos, não tinham o controle sobre a natureza, mas eram apenas uma de suas partes e "a sobrevivência de uma parte, depende da saúde de todas".

Com a necessidade de produzir, e com a consciência de que era preciso conservar o meio ambiente, surge a "gestão ambiental". Embora nas décadas de 70 e 80, devido ao agravamento do nível de degradação ambiental, as indústrias começassem a ter um controle ambiental, foi a partir 
da década de 1990 que a gestão ambiental começou a ser implantada de fato após a Eco-92 ocorrida no Rio de Janeiro, houve um aumento da assinatura de tratados e medidas normatizadoras tomadas pelos organismos financeiros internacionais configurando a construção de uma nova ordem mundial. A construção de um arcabouço normativo institucional ambiental nos Estados-nações é direcionada, em grande medida, pelo significativo número de acordos multilaterais relacionados com o meio ambiente que constituem o aspecto mais visível dessa nova ordem mundial, DIAS (2006).

$\mathrm{Na}$ busca pela melhoria da qualidade de vida, a indústria proativa assume o seu papel de corresponsável, tornando-se parceira de segmentos representativos da sociedade. Não basta que as empresas demonstrem apenas uma contínua melhoria na qualidade de seus serviços e produtos. Agora elas estão sendo pressionadas para demonstrar sua capacidade de oferecer produtos e serviços menos agressivos à saúde humana e ao meio ambiente.

A crise ambiental está intrinsecamente ligada ao desenvolvimento da sociedade humana como é concebida na atualidade capitalista; que trabalha com um pensamento fetichisado, corrompendo a visão social acerca das questões políticas, econômicas e de subsistência da população mundial; utilizando de maneira indiscriminada os recursos naturais para suprir suas necessidades, sem perceber que através desta postura, ceifa sua capacidade de sonhar e se torna uma sociedade sem propósito, sem utopia, imersa em uma "miséria da razão", justificada apenas pelo acúmulo da riqueza que busca o capital.

A gênese do pensamento fetichisado se deu com o serpentear do capital entre as relações sociais, políticas e de desenvolvimento econômico; que ao emergir e evoluir promove a sedução do ser humano e o entrega à um empobrecimento de sua ação, enquanto ser atuante de forma social, ato denominado "miséria da razão" por Coutinho (2010).

A sociedade humana corrompida por um pensamento fetichizado imediatista, não consegue compreender de forma adequada a degradação ambiental causada pela expansão capitalista, que promove o saque dos recursos naturais causando uma incerteza para a manutenção das gerações futuras; onde os impactos ambientais gerados pelo saque e depredação dos recursos naturais frente a ferocidade das forças capitalistas, suas indústrias e o atual modelo agrário de monocultura promove uma devastação visando gerir o lucro como fluxo vital.

Para LEFF (2007), "a Epistemologia ambiental é uma política do saber que busca a sustentabilidade da vida" e traz debates frequentes entre os pesquisadores por causa da busca do conhecimento científico. Segundo MORIN (2010), “... a ciência tornou-se poderosa e maciça instituição no centro da sociedade, subvencionada, alimentada, controlada pelos poderes econômicos e estatais". Por essa razão faz-se necessário o exercício de se pensar criticamente, como forma de encontrar novos horizontes entre a ciência boa que só traz benefícios e a ciência má que só traz prejuízos para derrubar essa "falsa" dicotomia que gera "... as estratégias de poder que se entrelaçam nos paradigmas científicos e na racionalidade da modernidade".

Até a década de 1960 prevalece a convicção de que seriam infinitas as fontes de recursos naturais e de que o livre mercado maximizaria o bem-estar social. Como a teoria econômica convencional tratava apenas de alocação de recursos escassos, e a natureza não era considerada fator de limitação, esse paradigma considerava o meio ambiente irrelevante para a economia. Apesar do absurdo de se raciocinar desta maneira nos dias de hoje, percebe-se ainda, a predominância desse conceito em certos segmentos da sociedade (TACHIZAWA, 2002).

O pensamento fetichizado, que será superado na medida em que se construir uma epistemologia ambiental concebendo os impactos ambientais como consequência do avanço capitalista só poderá ser desfeito à medida que os pesquisadores forem construindo uma cientificidade priorizando nela o desenvolvimento do mais alto nível de consciência proposta por LUKÁCS (2007), tal importância também foi ressaltada por MORIN (2010, p 21) onde a construção 
de uma ciência com consciência e com estratégias utópicas capazes de matar a morte engrenada pelo "veneno científico".

De acordo com SILVA \& CRISPIN (2011), nos últimos três séculos, a humanidade atingiu um alto nível de desenvolvimento tecnológico e por meio deste, tenta dominar, a forma de produção e controlar as reservas naturais que podem levar o homem a extinção. Com a intensificação das atividades do homem, o ritmo das mudanças acelerou e a escalada do progresso técnico humano pode ser medida pelo seu poder de domínio e transformação da natureza. Quanto mais rápido o desenvolvimento tecnológico, maior o ritmo de alterações provocadas no meio ambiente. Cada nova fonte de energia dominada pelo homem produz determinado tipo de desequilíbrio ecológico e de poluição.

O crescimento da produção industrial para suprir a demanda de consumo, fez surgir também as problemáticas ambientais, e um dos temas a ser tratado devido à possibilidade de ganho econômico e mitigação dos impactos ambientais e sociais, é o tratamento dos resíduos gerados nestes processos.

Com objetivo de levantar os principais aspectos da relação do desenvolvimento social e econômico da Humanidade, através de uma breve análise do histórico de exploração ambiental pela humanidade, para captação de recursos utilizados a seu favor em detrimento do respeito ao equilíbrio necessário para a manutenção da vida de outras espécies e da própria humanidade, a discussão e os resultados aqui expostos podem colaborar para o direcionamento de estratégias no gerenciamento dos resíduos e uso racional do meio ambiente.

\section{METODOLOGIA}

Com base no estudo da bibliografia apresentada foi possível realizar uma análise cultural, social e econômica frente à degradação ambiental, sendo concluído que uma mudança de paradigmas nos processos de exploração de recursos naturais é inevitável para a continuidade da vida humana e do equilíbrio ecológico do Planeta.

\section{RESULTADOS}

Frente à tantas argumentações científicas e econômicas estão os próprios índices de alterações em escalas planetárias como o aumento da temperatura, buraco na camada de Ozônio, Efeito Estufa, Poluição e a Extinção de muitas espécies que ainda podem nem ser conhecidas da humanidade. E todo esse processo se dá no decorrer da evolução sócio cultural humana, que se ampara em justificativas econômicas e científicas usadas de forma inescrupulosa para o desenvolvimento capitalista de uma porção minoritária da população humana.

A complexidade ambiental emerge como nova racionalidade e novo pensamento sobre a produção do mundo. É o espaço em que se articulam a natureza, a cultura e a técnica, e em que os atores sociais se mobilizam para a construção de estratégias alternativas de reapropriação da natureza. (LEFF 2003)

Para que possamos tratar os resíduos, dentre outras alterações na natureza, afim de chegarmos à soluções socioambientais contundentes, precisamos, de acordo com LEFF, trabalhar a discussão em torno da complexidade ambiental, que permeia duas categorias centrais dos processos socioambientais: a racionalidade ambiental e o saber ambiental, que pressupõem a articulação do conhecimento científico e o conhecimento extra científico (envolvendo os saberes culturais) para explicar os sistemas socioambientais complexos, no sentido de reconstruir o mundo frente às bases na relação entre sociedade e natureza.

Sendo assim, é visível que os novos sujeitos sociais, que estiveram envolvidos em movimentos ambientais, como Carson, emergiram como resposta à crescente destruição ambiental, caracterizando-se por suas formas de organização de luta e por suas influências no discurso que repercutem na esfera política e social. 


\section{DISCUSSÃO}

Em concordância com AB'SABER, e suas considerações em que, não se faz qualquer projeto de interesse em preservar o ambiente natural pensando apenas em favorecer de imediato só uma geração do presente, em termos de especulação com espaços ecológicos, mesmo porque, "somos de opinião que devemos pensar no sucesso de todos os grupos humanos, ao longo de muito tempo" e ainda acrescento que não só dos grupos humanos, mas de todas as espécies que compõem a biosfera e que possuem inter-relações intrínsecas com os fatores abióticos para a manutenção da vida no planeta.

Outro exemplo é a consideração da crise ambiental como degradação da qualidade de vida, estabelecendo assim, suas "interconexões" e não somente um problema de limites físicos ao desenvolvimento ou de contaminação técnica, como é comumente colocado pelas agências de desenvolvimento e muitos intelectuais do primeiro mundo. Todavia, é sabido que o papel dos movimentos sociais (camponeses, e outros) na construção dessa racionalidade ambiental alternativa, é proposto por LEFF, que considera uma série de questões dentre elas estão a dependência tecnológica e o processo de degradação ambiental como consequência do subdesenvolvimento e do desenvolvimento capitalista.

Fica muito claro, conforme exposto por Sachs (1994) que para colocar em prática esse desenvolvimento, é necessária uma criatividade ecológica a fim de auxiliar uma forma de pensar, de evidenciar a capacidade de grupos locais de ação não agressiva em relação ao meio ambiente e de retirar as barreiras (de natureza política e institucional) que impedem a possibilidade de uma ação, em longo prazo, a respeito da conservação. Assim, o ecodesenvolvimento tem sua ênfase nos espaços de autonomia local, vinculado a uma visão solidária para toda a humanidade.

\section{CONCLUSÃO}

As novas, desejáveis e impreteríveis interações entre sociedade e natureza acontecerão a partir da racionalidade ambiental e do saber ambiental apresentarem os subsídios que as ciências desconhecem, e a revalorização da diversidade cultural do conhecimento da realidade, que convoca a complexidade ambiental, não só no campo político, mas no campo epistemológico, que emergem entre o diálogo e a produção de novos saberes e conhecimentos.

Portanto, para construirmos uma relação dialógica, entre homem/natureza, é necessária a construção da racionalidade ambiental, como racionalidade produtiva alternativa pautada num processo político e social, para a formação do saber ambiental como nova perspectiva de análise das relações entre produção e conhecimento, chegando próximo de uma possível forma de utilização dos recursos naturais de maneira mais sustentável.

Pode-se considerar que para vários autores citados aqui como, AB'SABER, LEFF, MORIN e MUNIR que a complexidade da questão ambiental implica diretamente numa revolução ou reforma do pensamento, na quebra do "pensamento fetichisado" imposto pelo sistema capitalista vigente; e esta busca de mudanças de paradigmas, pautadas em pensamento complexo, apontam que o desenvolvimento sustentável apoiado em práticas de gerenciamento dos recursos naturais e educação plural que envolva ciência e saber popular atrelados ao respeito do ritmo do próprio ciclo da natureza, se anuncia como movimento dinâmico de construção e (re)construção de conceitos, ideias, práticas e valores para a compreensão das relações entre sociedade e natureza.

Através do gerenciamento e direcionamento dos resíduos gerados, a sociedade humana busca formas alternativas de trabalhar os recursos naturais de maneira mais produtiva sem desperdício dos recursos naturais, sabidamente que os mesmos são findáveis ou que seu ciclo natural possui um ritmo a ser respeitado antes de ser novamente explorado. 


\section{REFERÊNCIAS}

AB'SABER, N. A. Do Código Florestal para o Código da Biodiversidade. Biota Neotropica, 2010. http://www.biotaneotropica.org.br/v10n4/en/abstract?point-of-view+bn01210042010

CARSON, Rachel. Primavera Silenciosa. 3a reimp. São Paulo: Editora Gaia, 2013.

DIAS, R. Gestão ambiental: responsabilidade social e sustentabilidade. Atlas: São Paulo, 2006.

FELÍCIO, M. J. Apontamentos de Epistemologia Ambiental. In: Revista GEOAMBIENTE (on-line): Jataí-GO, n.21, jul-dez/ 2013, p.184-204, https://doi.org/10.5216/revgeoamb.v0i21.27844.

LEFF, Enrique. Complexidade, Interdisciplinaridade e Saber Ambiental. In: C.E.M., HOGAN, D.J.,

NAVEGANTES, Raul (editores), São Paulo: Signus, 2000, p. 19-51. . Complexidade ambiental. São Paulo: Vozes, 2003.

MORIN, Edgar. Ciência com Consciência. 13a edição. Rio de Janeiro: Bertrand Brasil, 2010.

SACHS, Estratégias de transição para o século XXI. In: BURSTYN, M. (Org.). Desenvolvimento sustentável. São Paulo: Brasiliense, 1994.

SILVA, V. B. da; CRISPIM, J. de Q. Um breve relato sobre a Questão Ambiental. Revista GEOMAE Geografia Meio Ambiente e Ensino. Vol. 02, nำ1, 1은.2011.

SEIFFERT, M. E. B. Gestão Ambiental; instrumentos, esferas de ação e educação ambiental. Atlas: São Paulo, 2007.

TACHIZAWA, T. Gestão ambiental e responsabilidade social corporativa: estratégias de negócios focadas na realidade brasileira. Atlas: São Paulo, 2002. 